\title{
Leer el mundo
}

\section{MARGOTH CARRILLO PIMENTEL}

\author{
Universidad de los Andes
}

Venezuela

“¿Es el libro hoy un objeto anacrónico?”. Con esa inquietante pregunta concluye el escritor venezolano Víctor Bravo Leer el mundo (2009), obra cuya razón de ser parece sustentarse fundamentalmente en la pasión por el libro y la lectura. Bravo, quien a lo largo de su ya extensa obra crítica y ensayística, ha asumido el papel de un extraordinario intérprete de la modernidad, ha encontrado en esa fuente del saber que es el cuestionamiento, el punto de partida y llegada a una amplísima y ambiciosa reflexión en torno al lenguaje, la escritura y la lectura. Frente a sus páginas, se tiene la impresión de que ahí nos aguardan las respuestas que veníamos buscando desde siempre, a propósito de temas fundamentales que sustentan, cruzan o rodean el acto de la lectura; sólo que esas respuestas han escogido y recorrido "el camino más largo" (Ricoeur) -el de la historia, el pensamiento, el arte o la literatura-para ofrecernos versiones distintas y provisionales del asunto que transitan cómodamente los extremos de la contundencia y de la duda.

Aporte de considerable importancia resulta para nosotros la revisión que en torno al sentido de la verdad expone el libro; argumentos que dan al lector elementos que propician una comprensión histórica de la evolución del pensamiento y ubican los puntos de inflexión que han hecho posible su transformación; distintos modos de configurarse y expresarse a lo largo del tiempo. Víctor Bravo encuentra en la figura del arco, la representación perfecta del proceso de la historia del pensamiento y de la consecución de la verdad: "caminos del bosque", parafraseando a Heidegger, que

1 Álabe $\mathrm{n}^{\mathrm{o}} 2$ - diciembre 2010

Para citar este artículo: Carrillo, M. (2010). Leer el mundo. Álabe, 2

ISSN 2171-9624

[ http://www.ual.es/alabe] 
conducen a la profesión de la fe y el encuentro con lo absoluto, propios de las sociedades míticas y religiosas -“encantadas”, como gusta llamarlas Bravo recurriendo a Weber- que pasan por la experiencia "optimista" de la objetividad y la ciencia de las sociedades modernas y que, en los últimos tiempos, nos han ofrecido visiones "en perspectiva" (Foucault), miradas históricas y parciales del mundo.

En ese breve y larguísimo recorrido que ofrece Leer el mundo, también podemos llegar a enterarnos de cómo el hombre ha escogido distintos medios para expresar o llegar a encontrar el sentido de la vida dentro o fuera de sí mismo: el relato -la voz-, el libro -la escritura- o el ordenador -la imagen-, terminan por convertirse en los instrumentos que privilegian una u otra versión del mundo y la realidad; además de constituirse, ellos mismos, en elementos fundamentales de la estructura del propio pensamiento. En lo que al libro respecta, Víctor Bravo ofrece las coordenadas de los lugares, momentos y sentidos cruciales de su aparición: es así como llegamos a tener una clara visión de su naturaleza moderna, de la significación del surgimiento de ese invento extraordinario de la modernidad, la imprenta, así como de la apertura con la que ahora el saber cuenta para constituirse en conocimiento y expresión esencial de la libertad y la ciudadanía.

"Por el libro, el mundo se hace conocimiento" (84), afirma Víctor Bravo al considerar el impacto de la aparición de ese medio en el escenario de la vida moderna; pero no sólo será el conocimiento objetivo, que luego se convertirá en otra expresión de control y poder, la extraordinaria oferta que el libro dejará en manos del lector. El valor más preciado de la modernidad, la libertad, hará posible, de igual modo, la exploración de otros ámbitos en los que la sujeción al nuevo orden tendrá como contraparte el cuestionamiento o la duda. En este sentido, la dimensión poética del lenguaje, entendida como poesis, abre posibilidades inmensas para la escritura y la lectura: en una suerte de encuentro extraordinario, la poesía provocará el encuentro entre, como bien lo ha expresado H.G. Gadamer (1993), "la pretensión de validez permanente" que adquiere o recupera- la palabra, gracias a su condición de escritura poética (20) y la superación de su naturaleza utilitaria o técnica. De alguna manera, el lenguaje, desde esa mirada en perspectiva que ofrece la poesía, recupera la noción y sentido de permanencia que tuvo para los antiguos la verdad, sólo que esta vez lo logra a cambio de un ejercicio dialéctico de escritura y lectura en el que la estabilidad, la cohesión y la corrección de 
la palabra son contrastadas o completadas por un ejercicio libre, de sentido crítico y naturaleza sensible, subjetiva.

Víctor Bravo apuesta en su libro a las inmensas posibilidades que da, entonces, la literatura moderna y, con ella, el surgimiento de la lectura como interpretación; acto de desciframiento en el que el silencio del intérprete no es mas que un delgado velo bajo el que se oculta la verdad: "El silencio que cubre como una burbuja el acto de la lectura -dice Bravo- transforma la experiencia espiritual de lo divino en experiencia estética. Y ese hombre que lee en silencio demanda un ámbito de silencio, un lugar apartado para, desde ese distanciamiento, poder ver mejor el mundo a través de su lectura y, a través del mundo y sus horizontes de letras, verse a sí mismo, a su mundo interno" (133). Innumerables son los ejemplos que la inmensa cultura literaria de Víctor Bravo puede aportar en éste y otros sentidos: así como la literatura latinoamericana forma parte de su sensibilidad y formación, la literatura universal constituye parte de su amplio y rico horizonte. Pienso que a este escritor sólo es posible comprenderle plenamente, si se comparte con él el placer de "leer [y comprender] el mundo" a través de eso que H.G. Gadamer llamó el "arte y la verdad de la palabra".

Para quienes miramos "el enigma de la lectura" desde el ámbito de la escuela, este libro ofrece ciertas claves para comprender-comprendernos en esa compleja tarea de convertir la enseñanza del lenguaje en una actividad libre, creativa y formativa. Todo forma parte, parece uno intuir luego de la lectura de este extraordinario y generoso libro, de una inmensa disposición para la fina escucha, de un extraordinario ejercicio de la sensibilidad y de una flexibilidad y apertura grandes frente a ese rostro imperturbable con el que suelen enmascararse las palabras y las cosas con las hemos dibujado la realidad o el mundo.

\section{Referencias:}

Bravo, V. (2009). Leer el mundo. Madrid: Veintisieteletras. 